\title{
MOVIMENTOS SOCIAIS E TRABALHO RURAL FRENTE ÀS TRANSFORMAÇÕES POLÍTICO-ECONÔMICAS E SOCIAIS NA AMÉRICA LATINA DO SÉCULO XXI
}

\author{
Everton Lazzaretti Picolotto* \\ Marco Antonio Teixeira * *
}

INTRODUÇÃO

O universo rural da América Latina foi historicamente marcado por processos econômicos e políticos de exploração de recursos naturais e commodities agrícolas, especialmente, para o mercado internacional. Nesses processos, os sujeitos políticos que vivem e trabalham no campo, muitas vezes, foram explorados como força de trabalho vil (como na escravidão, na servidão pessoal e nas várias formas degradantes de trabalho), expropriados das terras e dos recursos naturais de seu meio e excluídos, em grande medida, da distribuição dos valores gerados (Prado Jr, 1996; Martins, 1994; Fernandes, 2008; Quijano, 2013). Mesmo em condições muito adversas, os setores subalternos rurais não foram passivos, desde os tempos coloniais promovem resistências individuais e coletivas frente aos arbítrios, e

\footnotetext{
* Universidade Federal de Santa Maria (UFSM). Departamento de Ciências Sociais.

Av. Roraima, n. ${ }^{\circ} 1000$ - Campus Universitário, Prédio 74A

$2 .^{\circ}$ andar, sala 2230. Camobi. Cep: 97105900. Santa Maria

- Rio Grande do Sul - Brasil. everton.picolotto@ufsm.br http://orcid.org/0000-0003-4199-5553

** Freie Universität Berlin (FU Berlin). Instituto de Estudos Latino-americanos (LAI).

Boltzmannstraße 1. 14197 Berlim. Alemanha. marco.teixeira@fu-berlin.de

https://orcid.org/0000-0001-5794-4289
}

experimentaram formas de organização coletiva (messianismo, quilombos, exércitos populares, etc.) e enfrentaram os seus algozes (Huizer, 1969; Martins, 1981; Medeiros, 1989).

No século XX, em diferentes momentos, camponeses conquistaram, em alguns países, o acesso à terra por meio de amplas reformas agrárias radicais e populares (como no México - 1910-20, na Bolívia - década de 1950, em Cuba - 1950-60, Nicarágua - 1970-80), o estabelecimento de direitos trabalhistas rurais (como na Argentina com o Estatuto Del Peón Rural, de 1944, e no Brasil com o Estatuto do Trabalhador Rural, de 1963) e a organização de sindicatos de camponeses e trabalhadores rurais (em diferentes momentos nos distintos países) (Huizer, 1969; Medeiros, 1989; Ascolani, 2009; Barandiarán, 2009; Romero, 2019; Stedile, 2020).

Nas últimas décadas do século XX e início do século XXI, ganharam força diversos movimentos sociais rurais na América Latina, seja levantando bandeiras tradicionais dos agricultores familiares, camponeses e indígenas, tais como a reforma agrária e os direitos trabalhistas, seja elaborando novas ou renova- 
das demandas, tais como lutas por territórios tradicionais, por bens comuns, por reconhecimento dos povos originários, da agricultura familiar, dos camponeses, dos povos da floresta e das águas, das mulheres rurais, jovens, entre outros (Medeiros, 1989; 2014; Giarracca, 2002; Bartra, 2011; Rubio, 2017).

Esses movimentos conquistaram direitos e políticas públicas e obtiveram certo reconhecimento dos governos progressistas que chegaram ao poder em diversos países da América Latina, fenômeno comumente denominado de "onda rosa". Este processo teve início com a vitória eleitoral de Hugo Chávez na Venezuela (1998) e foi seguido por outras vitórias do campo progressista em diversos outros países, como no Chile (2000), Brasil (2002), Argentina (2003), Uruguai (2004), Bolívia (2005), Equador (2006), Nicarágua (2006), Paraguai (2008), El Salvador (2009). Em muitos destes lugares, estas forças se reproduziram no poder nos anos seguintes, como na Venezuela, Brasil, Equador, Argentina etc. (Pereira da Silva, 2014). As políticas promovidas neste contexto produziram transformações no meio rural latino-americano, muitas delas ampliando direitos, inclusive, no universo do trabalho e da organização política no campo.

No Brasil, por exemplo, organizações de agricultores familiares e de outros grupos subalternos do campo obtiveram algumas conquistas devido à proximidade com o grupo ন político no poder, como a criação e execução ऽิ de políticas públicas (crédito, compras estatais s. de produtos da agricultura familiar, habitação . rural, etc.) e o reconhecimento de alguns diç reitos (profissão de agricultor familiar, regu-

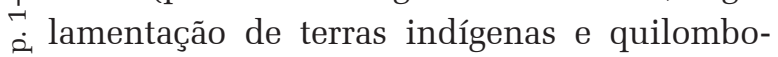
ले las, entre outras) (Abers; Bülow, 2011; Grisa;

Schneider, 2015; Medeiros, 2014; 2020). Outros casos considerados de sucesso na relação dos movimentos camponeses e indígenas com os governos progressistas são os da Bolívia e do Equador. Nestes países, com suas próprias particularidades, foram criados os chamados "Estados plurinacionais", garantindo aos po- vos e nacionalidades originárias/indígenas o pleno direito de conservar e desenvolver suas próprias formas de convivência e organização social, de geração e exercício da autoridade em seus territórios, de posse ancestral. Camponeses e indígenas destes países conquistaram, não sem contradições e conflitos, alguns direitos de cidadania e acessos aos recursos do Estado (Schavelzon, 2015).

No entanto, na última década, uma onda conservadora levou ao poder governos de direita e extrema direita na região. Esta onda atingiu países como Honduras (2009), Panamá (2009), Chile (2010), Paraguai (2012), Guatemala (2012), Argentina (2015), Brasil (2016), Peru (2016), Equador (2017), Colômbia (2018), Bolívia, (2019) e Uruguai (2019), entre outros. Com o novo ciclo de governos conservadores, muitas das conquistas dos atores políticos do campo estão sendo desmontadas e alguns deles têm sido alvo de diversos tipos de violência. As políticas desses governos têm promovido novas mudanças no meio rural, no sentido da diminuição da ação do Estado na garantia e proteção de direitos, com a desconstrução de arranjos políticos que beneficiam sujeitos políticos do campo (políticas públicas e direitos de cidadania), atingindo o mundo do trabalho com a aprovação de reformas trabalhistas e previdenciárias (no sentido do enfraquecimento da regulação pública e aumento da regulação privada) e as organizações políticas no campo (Niederle et al, 2019; Medeiros, 2020; Adascalieti; Pignatti Morano, 2016). Porém, este processo não é unívoco e, nos últimos anos, novos governos considerados progressistas têm chegado ao poder em alguns países da região, tais como: México (2018), Argentina (2019), Panamá (2019) e Bolívia (2020). A força e a organização dos movimentos sociais de trabalhadores, camponeses e indígenas foi central para esta ascensão de governos progressistas em alguns países, como na resistência ao golpe ocorrido na Bolívia em 2019.

As pesquisas sociológicas já produziram análises sobre algumas dessas transformações 
no universo rural latino-americano nas últimas décadas, sobretudo, quanto às implicações para o mundo rural, da ascensão e gestão de governos populares (Riella; Mascheroni, 2015; Delgado; Bergamasco, 2017; Neiman, 2016; Quaranta; Neiman, 2004; Sabourin et al., 2014; Medeiros, 2014, Rubio, 2017; Picolotto, 2018, Kay; Vergara, 2018, entre outras). Porém, ainda há pouco conhecimento acadêmico sistematizado e publicado sobre como a guinada política à direita em governos latino-americanos e as reestruturações produtivas e nos mercados de produtos agroalimentares em níveis locais e globais atingem o mundo do trabalho e a organização política rural. Esse dossiê busca suprir, em parte, esta lacuna ao reunir pesquisas e reflexões recentes sobre como estas transformações têm impactado no meio rural de diferentes países da região; como os sujeitos políticos experimentam estas mudanças, constroem suas demandas e fazem suas ações; quais as formas de relação com o Estado e com diferentes matizes de governos (progressistas e conservadores).

Os artigos deste dossiê lançam luzes para pensar o lugar do rural nas interpretações sobre as reconfigurações econômicas, políticas e sociais recentes na América Latina, seja em momentos de hegemonia do progressivismo (nos termos de Rubio e Peña, neste Dossiê) ou do conservadorismo. Os artigos mostram a centralidade da questão agrária, agroalimentar, da exploração de recursos naturais e commodities agrícolas para a compreensão das disputas políticas, econômicas e sociais na América Latina. O rural, muitas vezes visto como lugar de atraso ou setor que tenderia a desaparecer, é fenômeno central para entender o capitalismo contemporâneo na América Latina, o lugar da região na geopolítica global e os rumos políticos da região.

O artigo de Blanca Rubio e Jaime Peña inicia este dossiê com uma análise comparativa entre uma primeira onda de governos comprometidos com projetos alternativos na América Latina, os governos "populistas", da primeira metade do século XX, e uma segunda onda, os chamados governos "progressistas", do final do século XX e inícios do século XXI. Uma diferença fundamental é que, enquanto os populistas se apoiaram nas burguesias nacionais contra as oligarquias agrárias agroexportadoras, os progressistas precisam apoiar-se nas divisas geradas pelo agroextrativismo para financiarem os seus projetos de inclusão social e, com isso, contribuíram com os processos de reprimarização econômica, desindustrialização e fortalecimento dos setores extrativistas e agroexportadores, sem ancorar bases sólidas de sustentação político e econômicas. Para os autores, a queda nos preços das commodities na última década levou ao enfraquecimento da fonte de renda do progressismo, abrindo espaço para a ofensiva da nova direita que ascendeu por meio de golpes suaves em alguns países, assim como a ascensão eleitoral de líderes de direita em outros.

Leonilde Medeiros analisa as transformações ocorridas no campo brasileiros nas últimas quatro décadas, destacando como os atores dos setores subalternos do campo se conformaram (seja os agricultores familiares, assalariados rurais, sem-terras, etc.), os conflitos e alianças estabelecidas entre estes atores e suas organizações de representação, mas também como se configuraram em relação com políticas públicas e em embates com setores empresariais. Com isso, argumenta que para entender as transformações recentes no campo brasileiro é necessário romper com análises da representação política dos trabalhadores rurais que focam somente no estudo destes atores em si e sugere pensá-los em relação ao processo de crescimento e legitimação do que se denomina atualmente de agronegócio. A autora finaliza o texto constatando que, se por um lado há um recuo nas lutas no campo nos anos mais recentes, especialmente durante os governos conservadores, por outro lado está em curso um processo de alinhamento dos trabalhadores rurais com pautas focadas nos temas ambientais e em torno da alimentação saudável. 
O artigo de Ellen Corrêa também analisa transformações recentes no campo brasileiro, mas enfocando, sobretudo, no processo de formação de novas centrais sindicais no Brasil durante os governos do Partido dos Trabalhadores (PT). A autora mostra como no sindicalismo de trabalhadores rurais ocorreram diversas rupturas importantes de forças sindicais com a Central Única dos Trabalhadores (CUT) para dar impulso à formação de novas centrais e destas para atingir os índices de sindicatos filiados para o seu reconhecimento pelo Ministério do Trabalho. De outra parte, o texto também trata dos dilemas da Confederação Nacional dos Trabalhadores Rurais Agricultores e Agricultoras Familiares (Contag) para se readaptar a um cenário em que passaram a existir e serem reconhecidos outros agentes sindicais representantes de parcelas dos trabalhadores rurais, sejam eles agricultores familiares ou assalariados rurais.

Luciano Martinez Valle faz uma análise sobre o processo de proletarização de uma parcela dos membros das famílias camponesas absorvidas pelas atividades do agronegócio de flores e hortaliças, na serra equatoriana, província de Cotopaxi. Observa que as empresas não pretendem expropriar as famílias camponesas das suas pequenas áreas de terras (como ocorre em outras áreas de exploração agropecuárias capitalistas), mas sim mantê-las nas proximidades por perceberem vantagens nesta relação de pro¿ letarização e "semiproletarização" de membros ऽิ das famílias: redução de custos com transporte \&̊ e alojamento. As políticas de regulação pública do trabalho do governo progressista de Rafael Correa (2007-2017) não chegaram a consolidar $\therefore$ instrumentos de organização coletiva de trabafึ lhadores rurais nesta área e nos últimos anos, Com o governo de Lenín Moreno (2017-2021) e sob efeitos da pandemia da covid-19, foram feitas mudanças no sentido de flexibilizar as relações de trabalho, fragilizando ainda mais a organização coletiva e as condições de trabalho e reduzindo a remuneração dos trabalhadores do setor de flores e hortaliças.
No texto de Tomáz Palmisano, Juan Wahren e María Gisela Hadad, são tratados os atores e os conflitos extrativistas relacionados à mineração, ao agronegócio e aos hidrocarbonetos durante o governo Mauricio Macri (20152019), na Argentina. Os autores chamam a atenção para o fato que, durante este governo, foram realizadas diversas mudanças nas normas de controle e circulação para beneficiar a produção agropecuária de exportação, a mineração de grande escala e a exploração dos hidrocarbonetos. Se por um lado as grandes corporações foram estimuladas, por outro lado as comunidades locais foram desconsideradas, violentadas e, algumas vezes, despejadas das áreas de interesse. Os principais agentes que resistiram a usurpação dos territórios, a exploração predatória e poluição ambiental foram as comunidades indígenas, as organizações camponesas e as assembleias socioambientais locais.

As lutas dos movimentos de mulheres e feministas ganharam visibilidade em diversos países na América Latina em anos recentes com as mobilizações do Ni una a menos no Chile, a Campanha Nacional pelo Direito ao Aborto Legal, Seguro e Gratuito na Argentina e as ações do 8 de Março, Dia Internacional da Mulher, realizadas em todos os países da região. Neste Dossiê, este tema é abordado, com o foco na análise dos feminismos em contextos rurais. O artigo de Iolanda Araújo Ferreira dos Santos e Janaína Betto analisam as trajetórias políticas de mulheres no Movimento dos Trabalhadores Rurais Sem Terra (MST) e no Movimento de Mulheres Camponesas (MMC) para entender como suas articulações, elaborações e estratégias de resistência ajudam a compreender a conformação do chamado feminismo camponês e popular, variante do feminismo adaptado ao contexto do mundo rural e das lutas e resistências dos movimentos sociais camponeses frente à onda conservadora recente. Mesmo diante do avanço do neoconservadorismo (expressão utilizada pelas autoras em referência à formulação de Pinheiro-Machado, 2019) no Brasil, as mulheres destes movimen- 
tos buscam construir espaços de autonomia e esperança.

Já Marco Antonio Teixeira trata da Marcha das Margaridas, uma mobilização feminista do Brasil liderado pelas mulheres do campo, da floresta e das águas, organizada pelo Movimento Sindical de Trabalhadores e Trabalhadoras Rurais (MSTTR), em aliança com outros movimentos sociais, centrais sindicais e organizações internacionais. Mais especificamente, o autor analisa como o contexto de ascensão das novas direitas no país (no pós jornadas de junho de 2013, das mobilizações pelo impeachment da Presidenta Dilma Rousseff e com a eleição do governo Bolsonaro) influenciou a Marcha nas suas duas últimas mobilizações nacionais, em 2015 e 2019. Para construir sua análise, formula uma abordagem teórica que considera a análise da atuação dos movimentos sociais por meio dos conceitos de ações de reprodução social, formas de ação coletivas e oportunidades políticas. O trabalho conclui que a Marcha não é apenas a sua expressão mais visível, realizada na forma de uma grande protesto de rua na cidade de Brasília a cada quatro anos, mas também um longo processo de formação, organização, elaboração de uma agenda política e mobilização nos níveis locais e regionais e envolve uma política de alianças com outros atores sociais e contraposição a outros.

Boa leitura!

Recebido para publicação em 16 de abril de 2021 Aceito em 19 de abril de 2021

\section{REFERÊNCIAS}

ABERS, R.; BÜLOW, M.von. Movimentos sociais na teoria e na prática: como estudar o ativismo através da fronteira entre Estado e sociedade? Sociologias, Porto Alegre, ano 13, n. 28, set./dez. 2011, p. 52-84.

ADASCALITEI, D.; PIGNATTI MORANO, C. Drivers andeffectsoflabourmarketreforms: Evidencefrom a novel policycompendium. IZA J Labor Policy. 5, 15, 2016. https:// doi.org/10.1186/s40173-016-0071-z

ALMEIDA, Alfredo W. B. Terras tradicionalmente ocupadas: processos de territorialização e movimentos sociais. Revista Brasileira de Estudos Urbanos e Regionais, v. 6, n. 1, p. 9-32, 2004.

ASCOLANI, A. El sindicalismo rural em la Argentina: de la resistência clasista a la comunidad organizada (19281952). Bernal: Universidad Nacional de Quilmes, 2009.

BARANDIARÁN, L.O. Los Estatutos de Trabajadores Rurales: una comparación de los casos argentino e brasileño. Revista Espaço de Diálogo e Desconexão, Araraquara, v. 2, n.1, jul-dez, 2009.

BARTRA, A. Os novos camponeses: leituras a partir do México profundo. São Paulo: Leitura Acadêmica/Ed. Unesp, 2011.

DELGADO G.C.; BERGAMASCO, P. S. (Org.). Agricultura Familiar Brasileira: desafios e perspectivas de futuro. Brasília: MDA/NEAD, 2017.

FERNANDES, F. Sociedade de Classes e Subdesenvolvimento. 5 ed. São Paulo: Global, 2008.

GIARRACCA, N. Movimientos sociales y protestas em los mundos rurales latinoamericanos: nuevos escenarios y nuevos enfoques. Sociologias, n. 8, Porto Alegre, July/Dec, p.246-274, 2002.

HUIZER, G. Movimientos campesinos y reforma agraria en América Latina. Algunas generalizaciones preliminares. Revista Mexicana de Sociología, v. 31, n. 2, abril - junho de 1969, p. 387-416.

GRISA, C; SCHNEIDER. S. (org.) Políticas públicas de desenvolvimento rural no Brasil. Porto Alegre: Editora da UFRGS, 2015

KAY, C.; VERGARA, L. La cuestión agraria y los gobiernos de izquierda en América Latina: campesinos, agronegocio y desarrollismo. Buenos Aires: CLACSO, 2018

MARTINS, J.S. Os camponeses e a política no Brasil. Petrópolis: Vozes, 1981.

O poder do atraso. Ensaios de sociologia da história lenta. São Paulo: Hucitec, 1994.

MEDEIROS, L.S. História dos movimentos sociais no campo. Rio de Janeiro: FASE, 1989.

Sindicalismo rural nas últimas décadas: mudanças e permanências. In: OLIVEIRA, R.V.; BRIDI, M.A.; FERRAZ, M. (Org.). O Sindicalismo na era Lula: paradoxos, perspectivas e olhares. Belo Horizonte: Fino Traço, p.247282, 2014.

Movimentos sociais no governo Bolsonaro. Revista da ANPEGE, v. 16, p. 484-515, 2020.

NEIMAN, G. Mercados de trabajo y sindicalismo em producciones agrícolas reestructuradas de la Argentina. Trabajo y Sociedad, n. 27, p. 63-77, 2016.

NIEDERLE, P.A. et. al. Narrative Disputes over FamilyFarming Public Policies in Brazil: Conservative Attacks and Restricted Counter movements. Latin American Research Review, v. 54, p. 707-720, 2019.

PEREIRA DA SILVA, F. Quinze anos da onda rosa latinoamericana: balanço e perspectivas. Observador On-Line, v. 9, n. 12. Rio de Janeiro, 2014.

PICOLOTTO, E.L. Pluralidade sindical no campo? Agricultores familiares e assalariados rurais em um cenário de disputas. Lua Nova, v. s/v, p. 201-238, 2018.

PRADO JR, C. Formação do Brasil contemporâneo. 23. ed. São Paulo: Brasiliense, 1996.

PINHEIRO-MACHADO, R. Amanhã Vai Ser Maior: o que aconteceu com o Brasil e as possíveis rotas de fuga para a crise atual. São Paulo: Ed. Planeta do Brasil. 2019.

QUARANTA, G.; NEIMAN, G. Restructuring and functional flexibilization of agricultural labor in Argentina. Latin American Perspectives, n.137, 2004. 
QUIJANO, A. El trabajo. Argumentos v.26 n.72, may./ago. p.145-163, 2013.

RIELLA, A; MASCHERONI, P. (Org.) Asalariados rurales en América Latina. Buenos Aires: CLACSO, 2015.

ROMERO, A. G. O peronismo e o Estatuto del Peón Rural: relações entre estado e classes sociais no campo argentino durante o peronismo original. 2019. 211 p. Dissertação (Mestrado em História) - Programa de Pós-Graduação em História da Universidade Federal do Rio Grande do Sul.

RUBIO, B. A. El movimiento campesino en América Latina durante la transición capitalista, 2008-2016. Revista de Ciencias Sociales, n. 31, 2017, p. 15-38.
SABOURIN, E. et.al. Agricultures familiales em Amérique Latine: émergence, avancées et limites des politiques ciblées. Revue Tiers Monde, v. 220, p. 25-44, 2014.

SCHAVELZON, Salvador. Plurinacionalidad y VivirBien/ Buen Vivir: Dos conceptos leídos desde Bolivia y Ecuador post-constituyentes. Buenos Aires: CLACSO, 2015.

STEDILE, João Pedro (Org.) Experiências históricas de reforma agrária no mundo. v. 1. São Paulo: Expressão Popular, 2020, p. 15-28.

Everton Lazzaretti Picolotto - Doutor em Ciências Sociais pelo CPDA/UFRRJ. Professor do Departamento de Ciências Sociais da Universidade Federal de Santa Maria. Professor permanente do Programa de PósGraduação em Ciências Sociais e do Programa de Pós-Graduação em Extensão Rural da UFSM. Bolsista de Produtividade em Pesquisa do CNPq. Coordena o Grupo do Pesquisa Trabalho, Agricultura e Movimentos Sociais (TRAMAS). Possui experiência na área de Sociologia, com ênfase em Sociologia Política, Rural e do Trabalho, atuando principalmente nos seguintes temas: movimentos sociais, sindicalismo, trabalho, ruralidades, lutas por reconhecimento, agricultura familiar e agroecologia. Publicações recentes: Trabalho rural, representação classista e lutas por direitos na produção de maçãs em Vacaria-RS. Revista da ABET, 2020 (com Nadine Lermen); Narrative Disputes over Family-Farming Public Policies in Brazil: conservative attacks and restricted countermovements. Latin American Research Review, 2019 (com Paulo Niederle, Catia Grisa e Denis Soldeira); Pluralidade sindical no campo? agricultores familiares e assalariados rurais em um cenário de disputas. Lua Nova, 2018; Pluralismo, neocorporativismo e o sindicalismo dos agricultores familiares no Brasil. Sociedade e Estado, 2018.

Marco Antonio Teixeira - Doutor em Sociologia pelo Instituto de Estudos Sociais e Políticos (IESP) da Universidade do Estado do Rio de Janeiro (UERJ). Pesquisador de Pós-doutorado no Instituto de Estudos Latino-americanos (LAI) na Freie Universität Berlin (FU Berlin). Coordenador Científico do Grupo de Pesquisa Food for Justice: Power, Politics, and Food Inequalities in a Bioeconomy (LAI - FU Berlin), financiado pelo Ministério Federal de Educação e Pesquisa da Alemanha (BMBF), desenvolvendo pesquisas na área de sociologia política, sociologia dos movimentos sociais, sociologia do trabalho, sociologia da alimentação, sociologia rural, desigualdades sociais e estudos de gênero. Publicações recentes: Food movements, agrifood systems, and social change at the level of the national state: the Brazilian Marcha das Margaridas. Revista The Sociological Review (com Aline Borghoff Maia); Unionism and feminism: alliance building in the Brazilian Marcha das Margaridas. Revista Social Movement Studies (com Renata Motta). 